\title{
Well begun is half done
}

\author{
Euijune Kim $^{1}$
}

Published online: 2 March 2017

(C) The Japan Section of the Regional Science Association International 2017

As former president of the Korean Regional Science Association, as well as coeditor of both Annals of Regional Science and the International Journal of Urban Sciences, I would like to extend my congratulations on the historical launch of a new international journal, Asia-Pacific Journal of Regional Science. Asia and the Pacific regions have experienced tremendous economic and demographic structural adjustments over the last 70 years. In order to simply escape from widespread poverty, as well as to become key actors in the world's mainstream economy, they have tried to increase investment in education (human capital), infrastructure, and the R\&D sector. Also, with the help of government-driven industrial policies, they have sought to build transnational cooperative networks in terms of the flow of people, commodities, and information. However, not every region has not been able to realize these goals, due to spatial and resource disadvantages. Some regions are preparing for the arrival of the fourth industrial revolution, while others are striving to identify a solution to a regional economic slump in the middle of a second industrial revolution.

In general, whether a journal succeeds depends on its leadership and the composition of editorial board members. In this sense, with Professor Higano as editor-in-chief, well begun is half done for this journal. He has devoted his life to the passionate study of regional science. It would not have been easy to found this new journal without his determination and continuing sacrifice, not only to Japanese but international research as well. In addition, the editorial board features both seasoned masters in a wide range of fields and well-qualified young experts, so I am sure that the journal will provide us with myriad voices and perspectives on urban and regional themes concerning Asia and the Pacific regions.

Euijune Kim

euijune@snu.ac.kr

1 Department of Agricultural Economics and Rural Development, Seoul National University, Seoul, Korea 
There is no doubt that the APJRS will offer a venue for discussing research motivations and agendas, theoretical frameworks, and policy implications in response to the spatially heterogeneous problems of the Asia-Pacific regions. I believe that the journal will be not just a collection of peer-reviewed papers focusing on these regions, but will consistently arouse new ideas and inspire research goals and methods in its readers. Following a long tradition of regional science, the journal is expected to place a heavy emphasis on interpretation of spatial behavior and policies, using analytical tools and theoretical foundations in economics, geography, and planning in both Asia and the Pacific regions. As a consequence, it will provide valuable perspectives on the cause-and-effect relationships between space and the economic behavior of agents and institutions in the region, as well as how region-specific or local issues can be transformed or incorporated into international issues and perspectives.

I expect that each issue of the journal will be full of insightful articles, and that APJRS will, in the near future, join the ranks of regional science journals such as Papers in Regional Science and the Journal of Regional Science. 